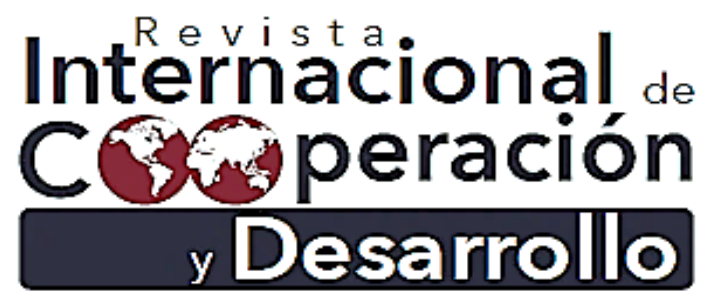

ARTÍCULO DE REFLEXIÓN

\title{
Marco Conceptual de la Cooperación Universitaria
} Conceptual Framework for University Cooperation

Fecha de recepción: | Junio de 2013

Fecha de aceptación: Enero de 2014

\section{Jairo Agudelo-Taborda}

Doctor en Filosofia Política, Ciencias políticas y Política Internacional. Especialista en Cooperación Internacional para el Desarrollo. Docente de la Universidad del Norte y Director de la Escuela Latinoamericana de Cooperación y Desarrollo. Dirección postal: Km. 5 Vía Puerto Colombia. Barranquilla, Colombia. Correo electrónico:tabordaj@uninorte.edu.co 


\title{
Resumen
}

El presente artículo responde a las preguntas sobre cómo surge la cooperación en el escenario internacional de actores naturalmente egoístas y cómo de ella deriva la cooperación internacional para el desarrollo llegando a ser su expresión más práctica y aplicada. Una vez establecido el marco teórico lógico y cronológico de la cooperación, el capítulo se adentra en el fascinante mundo de la universalización de las universidades mediante la aplicación de la cooperación por parte de ellas, no sólo en su afán de mayor visibilidad y calidad sino también en su voluntad de impactar sobre el desarrollo humano. Termina siendo un paseo por la fundamentación conceptual de la cooperación interuniversitaria ilustrado con algunos casos de academia cooperativa y competitiva a nivel global y regional.

Palabras clave: Cooperación internacional, Cooperación universitaria, educación superior.

\begin{abstract}
The chapter responds mainly to questions about how cooperation emerges in the international scenario with its naturally selfish actors and how it derives the international development cooperation becoming more practical and applied. Once the logical and chronological framework of cooperation is established, the chapter delves into the fascinating world of universal universities by implementing the cooperation from them, not only in an effort to have better visibility and quality but also in its will to impact on human development. It ends up being a walk on the conceptual basis of the inter-university cooperation illustrated with some cases of cooperative and competitive academy at the global and regional level.
\end{abstract}

Keywords: international cooperation, university cooperation, higher education. 


\section{INTRODUCCIÓN}

El objetivo de este breve artículo es el de ofrecer un cuadro de referencia conceptual y teórico sobre la cooperación universitaria como medio para generar nuevo conocimiento y difundir el ya existente con miras a promover el desarrollo humano de los individuos y de los pueblos.

Para enmarcar conceptualmente la cooperación universitaria es conveniente asumir lo que en este texto se entenderá por los dos términos de la cuestión: cooperación y universitaria. El primer término (cooperación) es un sustantivo puro y el segundo (universitaria) es un sustantivo adjetivizado que califica al primer término. Pero dado que la cooperación es una herramienta, en este caso hablar de la cooperación universitaria es referirse al uso que de ella hacen las Universidades. Por lo tanto, se inicia definiendo este concepto y luego el de cooperación por razones lógicas y cronológicas de manera tal que la secuencia sea: concepto de universidad; concepto de cooperación y, luego, concepto de cooperación universitaria.

Para ello, inicialmente se describen y analizan el concepto de universitas, relacionado con el origen de las primeras universidades. Luego, se revisa la forma en que adquiere la universidad el carácter de universal. Seguidamente, se explora el concepto de cooperación y su evolución desde el marco argumentativo de la teoría de las relaciones internacionales. Finalmente, se enlaza y revisa la cooperación universitaria dentro de la actual sociedad del conocimiento.

\section{UNIVERSITAS}

Según buena parte de las enciclopedias y de los diccionarios, el término universitas no nace asociado al conocimiento científico ni mucho menos a la universalidad de tal conocimiento. De hecho, el término deriva de la doble raíz etimológica latina unus, cuerpo único y versus, hacia, dirección. Podría entonces entenderse originalmente en el S. XIII la Universitas como una corporación de personas hacia un fin común. Para darle su connotación de organización para el conocimiento había que agregarle Scholarium o Magistrorum. De tal manera que las primeras universidades de la edad 
media como las de Bolonia, Oxford, Cambridge, Padua y París, se llamaron Universitas Magistrorum et Scholarium, entendida como corporación de Maestros y Alumnos.

Tales instituciones fueron al inicio religiosas y concernían los estudios mayores como la Teología, la Filosofía, la Medicina y el Derecho. El significado de Universitas como organización para el conocimiento sin necesidad de declinarla con Magistrorum y Scolarium, llega en el S. XIV. Así pues, es una paradoja de la historia que la Universitas como la conocemos hoy, abierta y certificable sea un producto medieval (Haskins, 1959), o sea, de la era mal llamada oscurantista. Sin embargo, instituciones de estudio existían ya en la antigüedad como las Escuelas Brahmánicas en Asia, el Liceo y la Academia de los griegos y la Escuela de Alejandría de Egipto; también las hubo desde el inicio de la Edad Media como la Escuela islámica Al Karouine en Marruecos (en el año 859), la Escuela Médica Salernitana (en el año 870 en Italia) y la Escuela Hunan en China (en el año 976); pero no eran abiertas ni su enseñanza estaba certificada y eran de carácter puramente privado.

En las primeras Universidades occidentales como la de Bolonia del 1088, fueron los estudiantes quienes se organizaron para contratar profesores sobre todo de Derecho. En París fueron los profesores quienes se organizaron para ofrecer sus cursos de Lógica y Teología. Terminó por imponerse el modelo de París incluso en la misma Bolonia, luego en Oxford, Cambridge y en las Universidades sucesivas. Así que eran de carácter puramente privado.

Podemos considerar que las primeras instituciones públicas de educación existieron en la era de la República Romana. Así mismo, hay suficiente consenso en considerar a la Universidad Al Azhar de Egipto como la Universidad más antigua del mundo pues fue creada en el 975 con grados y postgrados reconocidos por todo el mundo islámico y sigue siendo la más prestigiosa para los musulmanes ${ }^{1}$.

\section{UNIVERSITAS Y UNIVERSAL}

${ }^{1}$ Para mayor detalle consultar (www.azhar.edu.eg). 
La Universitas adquiere carácter de Universale con el conocimiento del Nuevo Mundo y luego con el Renacimiento: universal es tanto su objeto de estudio cuanto el sujeto y la entidad que lo estudia pues las instituciones se abren al mundo. Sus estudiantes provienen de todas las áreas geográficas y llegan a Italia, España, Portugal, Francia, Inglaterra y Alemania. Se estima que ya para el 1500 existían en Europa 70 Universidades. La Universidad era entonces una institución de enseñanza reconocida por las autoridades para otorgar grados y títulos ampliamente reconocidos.

A partir de entonces podemos decir que la Universidad se percibe como Universal. Tal concepción se consolidará ulteriormente con el nacimiento de la Ciencia (Keppler y Galileo) y del método científico como universalmente válido. No obstante, el mundo islámico considera que el método científico y la evaluación de sus productos a través de pares había nacido ya mucho antes, precisamente en la Escuela de Al Karouine de Marruecos entre los Siglos IX y X, período conocido como el Siglo de oro y el renacimiento del Islam (Kraemer, 1992) concomitante con la recuperación de la Filosofía griega por parte de los musulmanes Avicena y Averroes y retransmitida a Occidente.

En los Siglos XVI y XVII surgen, sobre todo en Inglaterra, instituciones especializadas en algunos sectores de la Ciencia que tomaron el nombre de Colegios (College Universitys) que dieron el paso hacia las actuales Universidades constituidas por facultades en una especie de ciudadelas con administración centralizada. Para América Latina, el modelo fue la Universidad de Salamanca creada en 1218 como Escuela (Studium), luego como Colegio Mayor y luego como Universidad en 1254. Bajo tal modelo se fundaron las primeras Universidades en América Latina: Santo Domingo (1538), México y Lima (1551). Las Universidades en América Latina nacen como Pontificias y Reales, mediante bula papal y cédula real.

En este período se redefinen conceptos básicos sobre la Universalidad y la Universidad:

- $\quad$ El conocimiento es universal en el sentido de que todo es susceptible de ser conocido y no sólo Dios y la Teología. 
- $\quad$ El método del conocimiento científico es universal

- $\quad$ La Ciencia es universal

- La institución que aplica el método científico al estudio del universo, generando Ciencia, es universal.

Aún los estudios particularmente religiosos que habían dado origen a las Universidades tanto del mundo judeo-cristiano como del islamismo o del lejano oriente (Japón, China e India) son considerados a valencia universal.

Es decir que objeto, sujeto y método de estudio se universalizan entre los siglos XV y XVI. Tal triple universalización se consolidará definitivamente para Occidente en el Siglo de las luces, la ilustración y el enciclopedismo (XVIII-XIX). En este mismo período la mayor parte de las universidades pasan a ser públicas en virtud de los principios de la Revolución francesa, sobre todo el de libertad de pensamiento. Esta libertad requería una educación libre y abierta. Surge así el modelo napoleónico de las universidades nacionales que se replicará luego en América Latina. Este sello se refleja en los nombres de buena parte de las universidades latinoamericanas: Universidad nacional, Central, Libre, Autónoma.

De hecho, en el 1826 se aprobó en la Gran Colombia la primera Ley republicana de organización de la educación durante la vicepresidencia de Francisco Santander. En 1830 se disuelve la Gran Colombia en tres Estados nacionales: Nueva Granada, Ecuador y Venezuela. Luego, con la Constitución de la Nueva Granada (1832), surgen las universidades oficiales como la Universidad Central de Bogotá, Universidad de Boyacá, Universidad del Cauca y Universidad del Magdalena con sede en Cartagena de Indias. Sin embargo, ya existían en la Nueva Granada (Colombia) las universidades privadas pontificias y reales según el modelo de Salamanca. La que hoy se conoce como Universidad Santo Tomás de Bogotá fue la primera, fundada por los Padres Dominicos en 1580 que ya habían fundado la primera universidad latinoamericana en Santo Domingo (La Española) en el 1538.

Así pues, hasta el siglo XVIII, el objetivo general de la Universidad era la difusión del conocimiento superior y por lo tanto su actividad central era la docencia. Es a partir del inicio del siglo XIX que las Universidades asumen el objetivo de 
generar nuevo conocimiento mediante la investigación. Este paso se le debe, sobre todo, al positivismo con el que nacen las Ciencias sociales al extender la aplicación del método científico también al estudio de los grupos humanos y no sólo a la naturaleza física o a las llamadas ciencias exactas. Augusto Comte resume los estadios del conocimiento humano hasta ese momento en tres etapas: la del conocimiento teológico, la del conocimiento metafísico y la del conocimiento positivo. La etapa positiva es la del método científico aplicado a todo el saber natural, individual y social. Así nacen las ciencias sociales que amplían el espectro del conocimiento como materia prima de las universidades: conocimiento ya existente (docencia) y nuevo conocimiento (investigación).

En Estados Unidos las primeras universidades fueron las ocho privadas que hoy constituyen la Liga de las hiedras (The Ivy League) de carácter deportivo desde 1954 pero que ya en el S. XVIII hacían intercambios de docentes: Harvard 1636, Yale 1701, Pensilvania 1740, Columbia 1754, Brown 1764, Darmouth 1769 y Cornell 1865. Las universidades públicas en los Estados Unidos pertenecen a los distintos Estados Federados y no al Gobierno nacional o federal, según la Décima enmienda de su Constitución. Particularmente representativas de universidades públicas son la Universidad de Virginia y el Instituto Tecnológico de Massachusetts (MIT).

Sin embargo, habría que esperar hasta el siglo XX para que la educación y el acceso al conocimiento fuesen reconocidos como derechos humanos universales.

\section{CONCEPTO DE COOPERACIÓN}

Gramaticalmente el término cooperación es el sustantivo del verbo cooperar que etimológicamente significa operar con..., o sea, actuar con otro u otros para un fin común. Por lo tanto, es sinónimo del término colaborar entendido como trabajar con... (Agudelo 2011).

La evolución del concepto de cooperación ha estado muy ligada a la del concepto de solidaridad desde los albores del derecho romano. Ya desde la república romana aparece la figura jurídica in solidum como responsabilidad asumida por 
varias personas respecto al debito (deuda) de cada persona y viceversa. Progresivamente, esta práctica pasó a significar bloque sólido en torno a los deberes de los débiles. Hoy significa hacer propia la causa de otro o de otros.

Esta evolución paralela de cooperación y de solidaridad dio origen a las cooperativas como modo común de producción en Inglaterra (Rochdale 1884) y en respuesta al individualismo del Estado liberal exasperado por la Revolución industrial. Esta experiencia colectiva se difundió por toda Europa hasta llegar a ser hoy la forma universal de economía solidaria que conocemos. (Agudelo, 2011).

La cooperación y la solidaridad han existido siempre como manifestaciones frecuentes aun desde las más arcaicas sociedades; pasando por las Órdenes Mendicantes de la Edad Media, los sindicatos y las Organizaciones humanitarias del Siglo XIX como la Cruz Roja Internacional. Pero la cooperación deviene praxis sistémica y pública a partir de la Sociedad de Naciones del 1919 en el marco del Tratado de Versalles que terminó la Primera Guerra Mundial y, sobre todo, con la Conferencia de Yalta y la adopción de la Carta de la Organización de las Naciones Unidas en 1945. El período entre las dos guerras mundiales marca la polarización de la eterna disputa entre competición y cooperación en las relaciones sociales. En la esfera política doméstica tal disputa había tenido nombres propios en el Siglo XVIII con Hobbes y Rousseau respectivamente que, sin embargo, convergen en la necesidad de un contrato social para moderar la natural propensión a la competición beligerante.

La competición pertenece a la esfera natural anárquica de los humanos y la cooperación a su esfera civil gobernada. La cooperación es un contrato social tácito o explícito. La clásica disputa entre competición y cooperación se trasladó en el siglo $\mathrm{XX}$ a la escena política internacional dando origen a las dos extremas teorías de las Relaciones Internacionales: liberalismo y realismo.

El liberalismo de Alfred Zimmern y Woodrow Wilson, siguiendo a Russeau, concibe los intereses de los Estados nacionales naturalmente armónicos. Tal armonía natural se rompe por un accidente en las relaciones de los Estados nacionales al intentar maximizar sus intereses aisladamente considerados. Se trata de una nota destemplada en un concierto natural. Tal accidente es la guerra. Para reconstruir la 
armonía perdida se requieren normas e instituciones comunes permanentes que impidan el accidente denominado guerra. Se requiere el contrato, el pacto, el tratado. Esta teoría inspiró el proyecto de la Sociedad de Naciones que duró veinte años (1919-1939).

El realismo, en cambio, afirma que los intereses de los Estados son naturalmente conflictuales debido a que surgen y se mueven en condición de anarquía. Esa es la situación real en la que se experimentan las relaciones entre ellos. Por lo tanto, el primer conflicto se genera en torno a su seguridad y a su subsistencia. Para ello dependen sólo de su propio poder de autodefensa determinado por la capacidad de sus armas. La guerra para el realismo no es un accidente sino la resultante fisiológica, como una ley natural, de la condición anárquica de los actores. Es inherente a la competición por su seguridad y supervivencia. Es instinto natural. La única vía para moderar la natural condición beligerante de los Estados es el equilibrio de fuerzas y de poder superlativamente expresado en las armas como se verificó durante la Guerra Fría. Los intereses naturalmente conflictuales de los Estados se manifiestan en términos de poder (Morgenthau, 1986).

Si el Liberalismo puede ser considerado ingenuo y utópico por su diagnóstico del contexto natural en el que se mueven los intereses de los Estados nacionales considerándolo armónico; el Realismo puede ser considerado trágico por la receta al atribuir al poder de la fuerza la moderación de la guerra pues equivale a decir que sólo la guerra puede impedir la guerra. $\mathrm{O}$, dicho de otro modo, que sólo la guerra puede procurar la paz.

Por tal razón, entre estas dos posiciones extremas se colocarán las nuevas teorías como la Neorrealista de Kenneth Waltz en su obra Theory of International Politics del 1979 y, sobre todo, la Neoliberal institucionalista de Robert Keohane y Joseph Nye en la que encuentra su mejor colocación teórica y conceptual la cooperación entre naciones. Keohane y Nye publican en 1977 la obra Power and Interdependence como respuesta a la máxima obra del realismo Politics Among Nations de Hans Morgenthau publicada en 1948. Para Keohane y Nye, el Realismo es una teoría estática que no da cuenta de la naturaleza cambiante del sistema 
internacional. No explica los procesos de integración económica y mucho menos la existencia de instituciones internacionales que en su teoría los dos autores llamarán regímenes internacionales en un contexto de interdependencia compleja (Keohane y Nye, 1988).

Pero, tal vez quien mejor responde al marco teórico de la cooperación en una posición cercana a Keohane y Nye es Robert Axelrod con sus obras The Evolution of Cooperation de 1984 y The Complexity of Cooperation de 1997. En la primera obra citada, Axelrod se pregunta ¿cómo es posible que entidades naturalmente egoístas como los Estados lleguen a cooperar? Mediante la teoría de los juegos y de la elección racional, ilustrada con el dilema del prisionero, explica que la cooperación calza perfectamente con la naturaleza egoísta y competitiva de los Estados.

La cooperación se verifica entre actores egoístas cuando ella misma representa en sí un interés, cínicamente hablando, de ellos. Efectivamente en el juego a suma cero propio de la competición pura hay necesariamente un perdedor absoluto y un ganador absoluto. En el juego a suma variable, propio de la cooperación, hay sólo ganadores relativos. No necesariamente hay perdedores y mucho menos perdedores absolutos. Además la mayor propensión a la cooperación se genera entre jugadores frecuentes, o sea, entre actores cuyas relaciones son asiduas. La novedad de Axelrod consiste en aclarar que para cooperar no se necesita ser altruista entendido el altruismo como renuncia a sus propios intereses. Se trata de otro tipo de intereses más sostenibles en el largo plazo y menos inmediatista. Los actores que cooperan pueden seguir siendo naturalmente egoístas pero cooperan al descubrir que las ganancias de otros son también sus ganancias. Tu bienestar tributa a favor de mi bienestar: Yo estoy bien, tú estás bien; vita tua, vita mea. Tal principio cambia el fundamento de las relaciones tradicionalmente basadas en la competición: yo estoy bien, tú estás mal; mors tua, vita mea.

Este es el concepto que subyace en la base, por ejemplo, de los acuerdos comerciales y de las instituciones internacionales que el Realismo no logra explicar quedándose anclada en la subjetividad única de los Estados individualmente considerados y obsesionados con el poder hegemónico en torno a su seguridad. 
Sin embargo las teorías institucionalistas y constructivistas comparten con el Realismo el diagnóstico de los intereses de los Estados como naturalmente conflictivos en condición de anarquía pero divergen de él en la receta para mantener la paz que adoptan, en cambio, del liberalismo. Se trata de la construcción de normas y de instituciones, mediante contratos sociales. Aún egoístamente a los Estados puede interesar construir la paz. Si la causa estructural de la guerra es la anarquía, se puede inferir lógicamente que la paz depende de la reducción y/o eliminación de la anarquía. Pero, en ausencia de un gobierno mundial, urge crear regímenes internacionales que gobiernen sectores sensibles a los intereses comunes como una especie de ministerios mundiales. Tales intereses comunes a escala universal se tipificaron a finales del Siglo pasado como bienes públicos globales. (Kaul, 1999).

De tal modo que la cooperación internacional se tipifica hoy como la política pública mundial para promover los bienes públicos globales en torno a los cuales convergen los intereses de los Estados ya sea por motivos solidarios y altruistas o sea, incluso, por motivos egoístas. Uno de los más importantes y consolidados bienes públicos globales es la educación.

Las instituciones y los regímenes internacionales se construyen mediante pactos que constituyen sus tratados, cartas o estatutos en el derecho internacional. Ahora bien, según Bobbio, el primer pacto que hacen los individuos y los grupos humanos es el pacto de no agresión o pacto negativo y mediante un proceso largo y dispendioso se transita hacia un pacto positivo, en el que ya no se trata sólo de evitar algo nocivo (la agresión) sino de cooperar para producir algo mutuamente útil (institución).

Las instituciones internacionales se tipifican como el mejor ejemplo práctico de pactos positivos, constructivistas. La ONU representa el pacto de no agresión a escala universal al prohibir la guerra mediante el artículo 2,4 de su Carta y, al mismo tiempo, el pacto positivo universal pues da inicio a la construcción del sistema multilateral de integración basado en la cooperación y en las relaciones pacíficas.

Todo esto ha sido posible porque en las naciones del mundo maduró una tácita o expresa percepción de la guerra como un mal general, un mal público. Se pasó de la 
inevitabilidad de la guerra como instrumento natural y normal de las relaciones entre naciones en condición natural a la percepción de un interés general superior, un bien público. Se trata de la transición del estado natural de las naciones a su estado civil.

Esta transición comportó el límite de la soberanía absoluta de los estados nacionales (modelo westfaliano anárquico) como precio a pagar por un bien común superior llamado paz segura. Los estados nacionales relativizan su soberanía, sin perderla, y se administran parte de ella en forma común y cooperativa (modelo yaltiano de la ONU). Transitan de la dependencia generada por la hegemonía de poder a la interdependencia voluntaria. Los Estados deciden libre y soberanamente de integrarse en organismos multilaterales creando regímenes internacionales y/o regionales. Los Estados adoptan otro modo de ejercer su soberanía basados en un pacto positivo que supera el pacto de no agresión y relativizando la condición natural de anarquía. Estos pasos se dan en virtud de la percepción colectiva y difusa de la existencia de bienes públicos universales como la seguridad y la paz opuestos a males públicos comunes como la amenaza y la guerra. Pero tal percepción llega a los Estados si y sólo si las naciones de los Estados, sus pueblos la maduran preliminarmente.

Es así que se verifica la demanda de instituciones $y$ de regímenes internacionales teorizada por Keohane, Nye y Axelrod en el Institucionalismo neoliberal. Ahora bien, las instituciones y los regímenes internacionales tienen la impelente responsabilidad de suplir la ausencia de un gobierno mundial central. Por tal razón, tienen la inaplazable tarea de generar políticas públicas que promuevan y garanticen los bienes públicos universales.

El objetivo general de la ONU según su propia Constitución (Carta ONU) en el artículo 1.1 es:

Mantener la paz y la seguridad internacional y con tal fin tomar medidas colectivas eficaces para prevenir y eliminar amenazas a la paz y para suprimir actos de quebrantamientos de la paz; y lograr por medios pacíficos y de conformidad con los principios de la justicia y del derecho internacional, el 
ajuste o arreglo de las controversias o situaciones internacionales susceptibles de conducir a quebrantamientos de la paz.

Esto significa que después de las dos guerras mundiales, un grupo de 51 naciones se asumieron la guerra como un mal público mundial y la paz como un bien público mundial. A tal concepción adhieren hoy 193 Estados nacionales que mediante la ratificación de la Carta de la ONU se abstienen de recurrir a las amenazas o al uso de la fuerza contra la integridad territorial o la independencia política de cualquier Estado, o en cualquier otra forma incompatible con los propósitos de las Naciones Unidas. (Artículo 2.4). Se trata nada menos que de la prohibición taxativa de la guerra.

La guerra deja de ser un instrumento lícito para las relaciones entre los Estados. Naturalmente, quedan tres excepciones:

- en el caso de legítima defensa;

- en el caso en que la fuerza sea usada por Ejércitos de Liberación Nacional contra una tiranía o una ocupación, y

- en el caso en que el uso de la fuerza sea autorizada por la ONU mediante resolución del Consejo de Seguridad. En tal caso se tipifica como una operación de paz que, como se aprecia, genera lógicas contradicciones al imponer la paz con la guerra autorizada por un organismo pacifista.

Como se ve, el proceso de interdependencia y de cooperación es complejo y a veces tortuoso. Depende de la voluntad de los Estados nacionales y la voluntad de estos depende, al menos en democracia, de la voluntad de las naciones, de los pueblos, de sus sociedades civiles que no siempre están cohesionadas y raras veces saben lo que quieren.

El resto del artículo 1 de la Carta ONU que enuncia sus propósitos subordina el mantenimiento de la seguridad y la paz (objetivo general) a dos condiciones (objetivos específicos) que consisten en la promoción de mejores condiciones de vida en el mundo y en la garantía del respeto a los derechos humanos a nivel universal sin distinciones. 
Sucesivamente, en el artículo 1.3 se establece el método y la estrategia para lograr los dos ambiciosos objetivos específicos y llegar así al objetivo general. Tal método es la cooperación:

Realizar la cooperación internacional en la solución de problemas internacionales de carácter económico, social, cultural o humanitario, y en el desarrollo y estímulo del respeto a los derechos humanos y a las libertades fundamentales de todos sin hacer distinción (...) (Carta ONU, artículo 1.3.).

Desde Kant en La paz perpetua (1795) hasta las recientes teorías, excepto la liberal, se coincide en reconocer que la paz no hace parte de nuestra dotación natural sino la guerra. Los realistas parecen condenar a las naciones a permanecer ancladas en la condición natural anárquica. Las demás teorías, sobre todo, el institucionalismo neoliberal y el constructivismo, afirman que precisamente por no haberla heredado de la naturaleza, la paz hay que construirla.

Así como los individuos en las sociedades nacionales han construido el leviatán, así los actores del escenario internacional construyen instituciones supraestatales para la paz. Bobbio, afirma en el texto ya citado, que el paso siguiente al pacto positivo en el proceso de cooperación entre actores naturalmente egoístas es el reconocimiento de árbitros inicialmente mediadores y luego jueces. Pues bien, el sistema internacional ha llegado hasta este nivel al dotarse de tribunales internacionales que juzgan Estados por violación de soberanía $\mathrm{y}$, sobre todo, por violación del Derecho Internacional de los derechos humanos.

Estos tribunales son las Cortes de derechos humanos de los organismos multilaterales regionales: Corte Europea en el Consejo de Europa, Corte interamericana en la Organización de Estados Americanos (OEA), Corte Africana en la Unión Africana (UA). Así mismo, el sistema internacional se ha dotado de Tribunales penales para procesar individuos por crímenes internacionales como genocidio, crímenes de guerra y crímenes de lesa humanidad. Inicialmente, en los años 1990, fueron tribunales limitados a casos específicos como el Tribunal Internacional para crímenes en Ruanda, en Ex Yugoeslavia y a partir del 2002 entró en vigencia la Corte Penal Internacional como tribunal permanente y sin límite 
geográfico o temporal que no sea la libre voluntad de ratificar el Estatuto de Roma por parte de los Estados nacionales.

La fase final del proceso, según Bobbio, es la certeza de la pena para quien viole o incumpla la certeza de la norma. O sea, la efectiva aplicación de las sentencias de los jueces en el Derecho Internacional que regula la sociedad mundial. Y éste es el más importante de los múltiples pasos faltantes del sistema internacional para completar el proceso de cooperación e integración.

Como se puede apreciar, la causa de la transición radica en la concepción de la dicotomía entre males públicos generales y bienes públicos generales. La adopción de los unos o de los otros depende de la voluntad general.

La teoría de los bienes públicos mundiales deriva del enfoque de bienes públicos nacionales elaborada por Paul Samuelson en su obra Teoría pura del gasto público de 1954. En extrema síntesis, Samuelson identifica las dos principales características del bien público respecto al bien privado: la no rivalidad y la no excluibilidad en su consumo. Por no rivalidad se entiende el hecho de que la ampliación de la cantidad de consumidores de un determinado bien no reduce los beneficios del consumo de ese bien para el total de sus consumidores. Por no excluibilidad, una vez provisto el bien, no es posible excluir de su consumo a ningún individuo.

De la distinción entre bien público y bien privado surge la asignación de la responsabilidad por proveer los bienes privados al mercado y la provisión de los bienes públicos al Estado. De ahí que se piense que sea ingenuo y utópico hablar de bienes públicos globales sin que exista el equivalente a un Estado mundial que los provea.

El constructivismo responde que, si bien es cierto que no existe un gobierno mundial centralizado no significa que no pueda existir en el futuro como fruto de la cooperación constructiva. Además, existe ya un sistema de instituciones y regímenes internacionales universales y regionales capaces de proveer dichos bienes públicos a escala universal (ONU) y a escala regional (UE, OEA, UA, ASEAN, LIGA ÁRABE). 
Para proveer bienes públicos se requieren políticas públicas y éstas requieren instituciones que las adopten.

En síntesis, identificado un bien público sensible por parte de las sociedades civiles estas demandan su provisión a las instituciones existentes o demandan la creación de nuevas instituciones si se carece de ellas.

Existe hoy un consenso universal en torno a un paquete de bienes públicos globales como la seguridad humana y la paz, el desarrollo humano, el ambiente sano, la estabilidad financiera, la democracia y los derechos humanos. Estos últimos incluyen el derecho a la educación que hace parte también de los ocho Objetivos de Desarrollo del Milenio asumidos en la Declaración del Milenio del 2000.

\section{COOPERACIÓN UNIVERSITARIA}

En las breves consideraciones iniciales hechas sobre la evolución del concepto de universidad hemos visto que a través de su historia éstas han sido prevalentemente privadas y por lo tanto basadas en la férrea competición entre ellas por el prestigio, el poder y el negocio. Entonces la educación era considerada un bien privado. Hemos visto, además, que hasta el Siglo XIX el objetivo de las universidades era el de difundir el conocimiento por lo que su función principal era la docencia.

Ahora bien, las empresas privadas tienen como objetivo generar ganancias pecuniarias. Las universidades privadas, por mucho tiempo, apuntaron a generar ingresos económicos mediante la docencia y por lo tanto se competían por los mejores docentes para concentrar prestigio y atraer al mayor número de estudiantes.

Con la inclusión de la investigación para la generación de nuevo conocimiento entre las funciones de las universidades, con el auge de las universidades públicas según el modelo napoleónico que se extiende en Europa y América Latina y, luego, con la adopción sistemática de la cooperación en la política doméstica y en las relaciones internacionales, también las universidades, frecuentemente egoístas por ser privadas, aprenden a cooperar tal como lo han hecho los individuos y las naciones.

Por mucho tiempo, también, la educación estuvo orientada hacia la guerra cuando ésta era considerada un medio lícito para dirimir las controversias entre los 
Estados. Así mismo, aún hoy, es mayor la financiación de la investigación para nuevos armamentos que aquella orientada a generar nuevo conocimiento para la convivencia pacífica entre los pueblos.

No obstante y muy a pesar de lo anterior, entre las dos guerras mundiales se crearon dos instituciones importantes para el impulso de lo que sería luego la cooperación universitaria. Se trata de la Comisión Internacional de Cooperación Intelectual (CICI) creada en Ginebra en el 1922; y la Oficina Internacional de Educación (OIE) también en Ginebra en el 1925.

Sin embargo, es la creación de la Organización de las Naciones Unidas para la Educación, la Ciencia y la Cultura (UNESCO), que consagra la progresiva cooperación universitaria. En las teorías vistas anteriormente de Keohane, Nye y Axelrod, la UNESCO se tipifica como el régimen internacional equivalente al ministerio universal para la educación, la ciencia y la cultura.

La UNESCO es creada en el 1945 en Londres y en su constitución contempla:

Los gobiernos de los Estados Partes en la presente Constitución, en nombre de sus pueblos, declaran que, puesto que las guerras nacen en las mentes de los hombres, es en la mente de los hombres donde deben erigirse los baluartes de la paz; que la amplia difusión de la cultura y la educación de la humanidad para la justicia, la libertad y la paz son indispensables a la dignidad del hombre y constituyen un deber sagrado que todas las naciones han de cumplir con un espíritu de responsabilidad y ayuda mutua... En consecuencia, crean por la presente la Organización de las Naciones Unidas para la Educación, la Ciencia y la Cultura, con el fin de alcanzar gradualmente, mediante la cooperación de las naciones del mundo en las esferas de la educación, de la ciencia y la cultura, los objetivos de la paz internacional y de bienestar general de la humanidad, para el logro de los cuales se han establecido las Naciones Unidas como proclama su Carta (UNESCO, 1945).

Como se aprecia en su Constitución, la Unesco concibe en 1945 la educación, la ciencia y la cultura como un medio para el logro de la paz y el bienestar general de la humanidad. Hoy la paz y el bienestar de la humanidad equivalen al desarrollo humano (Sen, 2010) que, en esta Carta, funge como objetivo general de la Unesco por lo que la 
educación, la ciencia y la cultura son sus objetivos específicos y la cooperación es el método. Este es el marco lógico de la cooperación universitaria.

La UNESCO no sólo insta a los Estados partes a cooperar para promover en el mundo la educación, la ciencia y la cultura sino que lo hace en nombre de sus pueblos. Por lo tanto, incluye a todos los actores constitutivos de las sociedades nacionales: Estado, Mercado y Sociedad civil. Las universidades cuando son públicas hacen parte del Estado, cuando son privadas se ubican en el Mercado y algunas funcionan como Fundaciones de la Sociedad Civil. Por tal razón, el mandato de la Unesco las cobija en todo caso, sobre todo por ser las instituciones diputadas a la docencia, a la investigación y a su impacto social.

La cooperación universitaria se realiza por al menos dos canales: el nacional y el internacional.

El canal nacional o doméstico de la cooperación universitaria consiste en las interacciones más o menos sistemáticas y permanentes entre las Instituciones de Educación Superior (IES) del mismo país como es el caso de Asociación Colombiana de Universidades, ASCUN Colombia, con sus diferentes nodos regionales. Por este canal la cooperación puede ser interuniversitaria pura o mixta según que la cooperación sea sólo y exclusivamente entre IES o entre éstas y otras entidades como las empresas o las Organizaciones de la Sociedad Civil (ONG'S y asociaciones).

El canal internacional de la cooperación universitaria está conformado por las interacciones entre las IES a escala regional y/o mundial y por las actividades conjuntas entre las IES y otros actores internacionales como los Estados, las Organizaciones Multilaterales, las Empresas multinacionales, las Organizaciones Internacionales No Gubernamentales, las Fundaciones Internacionales e, incluso los Individuos.

Así que la cooperación universitaria internacional usa todas y las mismas tipologías de la cooperación internacional para el desarrollo: bilateral, multilateral, descentralizada, no gubernamental, Sur-Sur y triangular. Se trata, pues, de aplicar tal complejo y sofisticado subsistema de las relaciones internacionales a la cooperación educativa. 
Por vía bilateral los países que más realizan cooperación universitaria internacional son Estados Unidos, Francia e Inglaterra. Por la vía multilateral las principales actrices son la ONU y la Unión Europea.

El experto en materia, Jesús Sebastián Cooperación e internacionalización de las universidades publicado en el 2004 propone la siguiente definición:

La cooperación internacional universitaria como ámbito especifico de la cooperación internacional, se refiere al conjunto de actividades realizadas entre instituciones universitarias que, a través de múltiples modalidades, implica una asociación y colaboración en temas de política y gestión institucional; la formación, la investigación, la extensión y la vinculación para el mutuo fortalecimiento y la proyección institucional; la mejora de la calidad de la docencia; el aumento y la transferencia del conocimiento científico tecnológico; y la contribución a la cooperación para el desarrollo (Sebastián, 2004).

Como se aprecia en la definición adoptada, tiene dos tipos de objetivos: uno interno a las IES mismas que consiste en su fortalecimiento institucional y otro externo consistente en maximizar la cantidad y la calidad de su impacto social. Se presupone que el fortalecimiento institucional comporte una mejor calidad de las funciones sustantivas históricas de las universidades como la docencia y la investigación y que ésta comporte, a su vez, el cumplimiento de su objetivo externo.

El proceso de mundialización de las sociedades ha involucrado en primera fila a las universidades convirtiéndolas en actrices de la cooperación internacional para el desarrollo hasta llegar a la adopción de la estrategia global de cooperación internacional para la Investigación y el Desarrollo conocida como $C I I+D$.

El proceso de internacionalización de las universidades ha acompañado toda la historia de estas instituciones de educación superior pues desde sus orígenes, como ya se ha dicho, tanto los docentes como los estudiantes acudían a ellas provenientes del mundo hasta entonces conocido. Tal proceso se aceleró con el reconocimiento del nuevo mundo de las Américas.

La internacionalización de las universidades consiste, entonces, en un conjunto de actividades para la transformación institucional que integre la dimensión mundial e 
intercultural en la misión, la visión, la cultura, la política y la estrategia de las universidades mismas. Tal proceso, si bien inicia con actividades concretas de intercambio de docentes, investigadores, estudiantes, cátedras y tecnologías que ha existido siempre; va más allá al incorporar el enfoque internacional a su misión y visión y no sólo a sus actividades, es decir a su ser universidad y no sólo a su qué hacer universitario.

En este sentido la internacionalización de las universidades se verifica cuando éstas se asumen responsablemente el mundo con sus méritos y sus límites y, sobre todo, con sus agudos problemas. Luego, la cooperación universitaria es necesariamente cooperación para el desarrollo humano sostenible y por lo tanto se asume como propio el sistema de cooperación internacional declinándolo en cooperación educativa en armonía con la integración regional y universal actualmente en construcción como ya lo hemos visto enmarcado en las teorías de las relaciones internacionales, en especial en el institucionalismo constructivista de Kaohane, Nye y Axelrod.

Así lo interpreta, además, la Declaración Mundial sobre la Educación Superior en el Siglo XXI: visión y acción adoptada por la Unesco a Paris en el 1998 en cuyo preámbulo se lee:

(...) en los albores del nuevo siglo, se observa una demanda de educación superior sin precedentes, acompañada de una gran diversificación de la misma, y una mayor toma de conciencia de la importancia fundamental que este tipo de educación reviste para el desarrollo sociocultural y económico y para la construcción del futuro, de cara al cual las nuevas generaciones deberán estar preparadas con nuevas competencias y nuevos conocimientos e ideales.

En la Conferencia Mundial sobre la Educación Superior de la UNESCO en el 2009 titulada Las nuevas dinámicas de la educación superior y de la investigación para el cambio social y el desarrollo se confirmó lo adoptado en 1998 y se decantó en las siguientes actividades en las que debe estar comprometida la cooperación internacional al desarrollo en general y en especial la cooperación universitaria:

- Internacionalización, regionalización y globalización 
- Aprendizaje, investigación e innovación

- Acceso, equidad y calidad

- Responsabilidad social de la educación superior

En virtud de tal secuencia lógica, la cooperación universitaria no escapa a la corresponsabilidad global en torno al logro de los Objetivos de Desarrollo del Milenio asumidos como bienes públicos globales. Por lo tanto, también la cooperación universitaria será sometida a examen en el 2015 como lo será el entero sistema mundial de cooperación.

Consecuentemente, como se ve, la cooperación universitaria termina haciendo parte de los procesos de integración regional y subregional. Todos los procesos de integración regional de los organismos multilaterales ubican al centro de su estrategia la cooperación educativa y muchos de ellos aspiran a constituir espacios comunes de educación en general y, en especial, de educación superior. De esto dan prueba los organismos regionales europeos y latinoamericanos.

El 25 de mayo de 1998 se adoptó en París la Declaración de La Sorbona titulada Declaración conjunta para la armonización del diseño del Sistema de Educación Superior Europeo, en la que se lee: Recientemente, el proceso europeo ha dado pasos de extremada importancia. A pesar de la relevancia que ello tiene, no deberíamos olvidar que al hablar de Europa no sólo deberíamos referirnos al euro, los bancos y la economía, sino que también debemos pensar en una Europa de conocimientos. Es deber nuestro el consolidar y desarrollar las dimensiones intelectuales, culturales, sociales y técnicas de nuestro continente. Éstas han sido modeladas, en gran medida, por las universidades, quienes todavía desempeñan un papel imprescindible en su desarrollo.

El 19 de junio de 1999 en Bolonia, Italia, considerada la más antigua universidad europea, se adopta la Declaración conjunta de los Ministros Europeos de Educación para la Creación de un espacio social y cultural común, una Europa del conocimiento. En su preámbulo, la Declaración de Bolonia afirma que Universalmente, se consideran sumamente importantes la educación y la cooperación 
educativa para el desarrollo y fortalecimiento de sociedades estables, pacíficas y democráticas.

El proceso de Bolonia se enmarca en una doble visión del mundo y de Europa: la coyuntural y la futurible. Coyunturalmente, la Declaración de Bolonia se da en un mundo post-bipolar a diez años de la caída del Muro de Berlín que puso fin a la Guerra Fría y en una Europa en fuerte proceso de integración siete años después del Tratado de Maastricht que decretó el tránsito de las Comunidades Económicas Europeas hacia la Unión Europea.

Futuriblemente, la creación de un espacio social y cultural común y una Europa del conocimiento que proyecta el continente hacia el mundo del nuevo milenio. Para ello se empieza a tejer el proyecto de una Constitución común para los ciudadanos europeos, una ciudadanía única. Tal proyecto se presentó en la reunión del Consejo Europeo realizada en Salónica (Grecia) en el 2003.

El proyecto no se ha realizado pues no ha obtenido las ratificaciones por parte de los Estados necesarias para entrar en vigor pues en algunos de los países en los que se ha sometido a referéndum ha ganado el voto por el no. Sin embargo, vale la pena destacar lo que contempla el Artículo 3.3 como uno de sus objetivos:

La Unión obrará en pro de una Europa caracterizada por un desarrollo sostenible basado en un crecimiento económico equilibrado, en una economía social de mercado altamente competitiva, tendente al pleno empleo y al progreso social, y en un nivel elevado de protección y mejora de la calidad del medio ambiente. Asimismo, promoverá el progreso científico y técnico.

Por lo que se refiere a la región latinoamericana su proceso de integración ha estado siempre en su agenda desde los albores de su independencia y constitución de sus Estados nacionales en la primera mitad del Siglo XIX conocido como ideario bolivariano y panamericanismo.

En 1910 en la Conferencia de Buenos Aires nace oficialmente la Unión Panamericana y en 1948 en la Novena Conferencia Panamericana en Bogotá nace la Organización de Estados Americanos. En ella y en todos los procesos de integración subregional (CAN, MERCOSUR, AEC, SICA, CARICOM, UNASUR, ALBA Y 
CELAC, entre otras.) la cooperación educativa para el desarrollo ha estado transversalmente presente al menos en términos declaratorios de principios e intenciones. Tal incertidumbre y retórica hace parte de los altibajos que históricamente han acompañado todos los procesos de integración regional y subregional latinoamericanos y caribeños. Por ello, no es de extrañarse.

Los casos históricos y significativos de cooperación universitaria regional latinoamericana es el de la Unión de Universidades de América Latina (UDUAL) creada en 1949; el Convenio Andrés Bello vigente desde 1970 y la Organización Universitaria Interamericana (OUI) desde 1979 y la Red Latinoamericana. Sin embargo, la concepción de un Espacio Latinoamericano y caribeño de educación superior es reciente y se ha hecho sensible siguiendo las huellas europeas a partir de la Declaración de Bolonia del 1999.

Tal proyecto ha intentado declinarse en propuestas como la del Espacio Iberoamericano del Conocimiento adelantada por el Consejo Iberoamericano de Universidades, CUIB, la Organización de Estados Iberoamericanos (OEI) y la Secretaría General Iberoamericana (SEGIB) con el auspicio de los gobiernos de los países iberoamericanos y sus respectivas redes de universidades.

La Conferencia Económica para América Latina y Caribe (CEPAL) ha promovido la creación de un Espacio Latinoamericano y Caribeño de Educación Superior con el apoyo de la Unión Europea y sus proyectos regionales de cooperación educativa como Alfa, Alban y Erasmus Mundus. A este proyecto ha adherido los actores de financiación de la cooperación internacional como el Banco Mundial, el Banco Interamericano de Desarrollo (BID), el Comité de Ayuda para el Desarrollo de la Organización para la Cooperación y el Desarrollo Económico (OCDE), la Agencia de Estados Unidos para la Cooperación al Desarrollo (USAID), entre otros.

El avance del marco teórico y conceptual de la cooperación universitaria para la Investigación y el Desarrollo (I + D) en la región, así como en el mundo, ha sido propiciado por el Instituto Internacional para la Educación Superior en América Latina y Caribe (IESALC) de la UNESCO. En el IESALC se ha creado el espacio de 
Encuentro Latinoamericano y Caribeño de Educación Superior (Enlaces) como red de redes de cooperación e integración educativa regional.

Este rol le ha sido asignado al IESALC, sobre todo, a partir de la Conferencia Regional de Educación Superior (CRES) realizada en el 2008 en Cartagena de Indias, Colombia como se expresó en la Declaración titulada Desafios locales y globales: una agenda estratégica para la educación superior en América Latina y Caribe. E1 IESALC de la UNESCO, con sede en Caracas, se ha constituido en un referente fundamental para hacer un atento seguimiento a la evolución de la cooperación universitaria y educativa en América Latina y de la calidad de la educación superior en la región (iesalc.unesco.org.ve). Sus publicaciones son de gran interés y valor científico pedagógico. Para el IESACL de la UNESCO, la educación es un bien público mundial y un derecho humano universal.

Para hacer realidad este principio a nivel mundial y regional se ha creado un buen número de redes universitarias en todos los continentes que serán objeto de otro escrito en esta publicación. Aquí se mencionan algunas como Universia, el programa Unitwin, University Twining, Ivy League, Red Latinoamericana de Cooperación Universitaria, Unión de Universidades de América Latina (UDUAL), el Programa CYTED de cooperación universitaria Iberoamericana, el Observatorio de Cooperación Universitaria Iberoamericana y otros.

La cooperación universitaria ha generado un rico patrimonio en investigación y formación sobre la cooperación internacional para el desarrollo de tal manera que hoy se puede afirmar sin exagerar que ésta se ha convertido en una disciplina dentro del estudio de las Relaciones Internacionales, de la Ciencia política y de las Ciencias Sociales. Esto explica la existencia de un cada vez mayor número de postgrados sobre cooperación internacional para el desarrollo incluyendo el nivel de doctorado en Norteamérica y en Europa.

\section{REFLEXIONES FINALES}

Se concluye este breve escrito con las preguntas que la UNESCO se planteó en la Conferencia mundial de Educación Superior en el 2009, en Paris: 
¿Hasta qué punto la educación superior es hoy día la conductora del desarrollo sostenible en los contextos nacional e internacional? ¿Responde la educación superior a las expectativas puestas en ella para inducir cambio y progreso en la sociedad y para actuar como uno de los factores claves para la construcción de sociedades basadas en el conocimiento?

Estos son los desafíos que afrontan las universidades en su ser Instituciones de Educación Superior, en su qué hacer universitario, en su internacionalización, en su cooperación universitaria en la era del conocimiento y en la nueva cooperación internacional que se implementará después del 2015.

\section{BIBLIOGRAFÍA}

Agudelo (2011) Variables sociopolíticas de la cooperación internacional para el desarrollo en América Latina y Caribe, Editorial Bonaventuriana, Cartagena.

Axelrod, R y Keohane, R. (1985). Achieving Cooperation under anarchy: Strategies and institutions. World Politics, vol. 38, n. 1 (octubre), pp. 226-254

Gacel-Ávila J. (2006) La dimensión internacional de las universidades, Contexto, Procesos, Estrategias, Universidad de Guadalajara-CONAHEC, 2006, pp.320.

Homer Haskins, Charles (1959). The rise of the Universities, New York.

Kraemer, J. (1992). Humanism in the Renaissance of Islam, Brish Publishers.

Keohane, R. (1993). Instituciones Internacionales y poder estatal: ensayos sobre teorías de las relaciones internacionales. Grupo Editorial Latinoamericano, Buenos Aires.

Keohane, R. y Nye, J. (1988). Poder e interdependencia: la política mundial en transición. Grupo Editorial Latinoamericano, Buenos Aires.

Keohane, R. (1988). Después de la hegemonía. Cooperación y discordia en la economía política mundial. Grupo Editorial Latinoamericano. Buenos Aires.

Cobban, A. B., "Universities: 1100-1500", en The Encyclopedia of Higher Education, Edited by Burton C. Clark and Guy Neave, Pergamon Press, 1992.

Educación superior en América Latina: la dimensión internacional. Banco Mundial 2005

Frijhoff, W "Universities: 1500-1900", en The Encyclopedia of Higher Education, Edited by Burton C. Clark and Guy Neave, Pergamon Press, 1992.

Kaul, I., Grunberg, I., Stern, M. (1999). Global Public Goods. Oxford University Press, New York. 
Bobbio, N. (1984). El futuro de la democracia. Plaza y Janés.

Sen, A. (2010). La idea de la justicia. Santillana, Ediciones Generales, México.

Sebastian, J. (2004). Cooperación e Internacionalización de las Universidades. Editorial Biblos, Madrid.

UNESCO (2009): Declaración Mundial sobre la Educación Superior en el siglo XXI: Visión y Acción.

Sebastián, J. (2003) Estrategias de cooperación universitaria para la formación de investigadores en Iberoamérica Organización de Estados Iberoamericanos para la Educación, la Ciencia y la Cultura (OEI). 